\title{
A POLÍTICA EXTERNA COMO POLÍTICA PÚBLICA? DIÁLOGOS ENTRE ESTUDOS POLÍTICOS E ESTUDOS INTERNACIONAIS ${ }^{1}$
}

Pedro Ponte e Sousa ${ }^{2}$

\begin{abstract}
Resumo
Neste trabalho procuraremos levar a cabo uma análise preliminar da abertura e das conexões entre duas áreas dos estudos políticos e internacionais: a política externa e as políticas públicas. Tentou-se analisar, por um lado, de que forma ambas vêem o Estado e a tomada de decisões neste; por outro lado, discutir os posicionamentos mais comuns das teorias fundadoras das Relações Internacionais e das Políticas Públicas relativamente às suas percepções da política externa e da definição do seu próprio campo de estudo. Seguidamente, tentou-se compreender, relativamente à Foreign Policy Analysis, se esta se apresenta como uma aproximação ao conhecimento das Políticas Públicas, e até que ponto é visível, nesta última área, uma abordagem que procure acercar-se, do mesmo modo, do conhecimento dos fenómenos internacionais como tendo impacto no processo de tomada de decisão interno (nacional). A revisão crítica da literatura de ambas as áreas levar-nos-á a concluir que há ganhos significativos, para ambas as disciplinas científicas, em termos de uma melhor compreensão e explicação dos fenómenos que analisam, tendo assim em conta um conjunto de influências e actores mais alargados do que os normalmente estudados e descritos.
\end{abstract}

Palavras-chave: estudos políticos; estudos internacionais; política externa; políticas públicas

\begin{abstract}
In this work we seek to carry out a preliminary analysis of the opening and the connections between two areas of political and international studies: foreign policy and public policy. We attempted to examine, firstly, how they see both the state and decision-making in it; on the other hand, discuss the most common positions of the founding theories of International Relations and of public policy regarding their perceptions of foreign policy and the definition of their own field of study. Next, we tried to understand in relation to Foreign Policy Analysis, if it could be seen as an approach closer to the knowledge in public policy, and to what extent is visible, in the latter area, an approach that seeks, in the same way, to move closer to the knowledge of international phenomena as having an impact on the internal (national) decision-making process. A critical review of the literature from both areas lead us to conclude that there are significant gains to both scientific disciplines, in terms of better understanding and explanation of the phenomena analyzed, thus taking into account a wider range of influences and actors than those normally studied and described.
\end{abstract}

Keywords: political studies; international studies; foreign policy; public policy

\section{Resumen}

En este trabajo tratamos de llevar a cabo un análisis preliminar de la abertura y las conexiones entre dos áreas de estudios políticos e internacionales: la política exterior y la política pública. Hemos tratado de examinar, en primer lugar, cómo perciben el estado y la toma de decisiones en este; por otra parte, discutir las posiciones más comunes de las teorías fundadoras de Relaciones Internacionales y Políticas Públicas en cuanto a sus percepciones de la política exterior y la definición de su propio campo de estudio. A continuación, tratamos de entender, en relación al Foreign Policy Analysis, si se presenta como una aproximación a la comprensión de las políticas públicas, y en qué medida es visible, en esta última área, un enfoque que busca acercarse, a la misma manera, el conocimiento de los fenómenos internacionales como teniendo un impacto en el proceso de toma de decisiones interno (nacional). Una revisión crítica de la literatura de ambas áreas nos llevan a la conclusión de que existen beneficios significativos, para ambas disciplinas

\footnotetext{
${ }^{1}$ DOI deste artigo: http://dx.doi.org/10.5380/recp.v5i2.37412

${ }^{2}$ Mestrando em História, Relações Internacionais e Cooperação na Faculdade de Letras da Universidade do Porto (FLUP). Licenciado em Línguas e Relações Internacionais pela mesma faculdade.
} 
científicas, en términos de una mejor comprensión y explicación de los fenómenos analizados, teniendo así en cuenta una serie de influencias y actores más ancha que los habitualmente estudiados y descritos.

Palabras clave: estudios políticos; estudios internacionales; política exterior; políticas públicas

\section{INTRODUÇÃO. JUSTIFICAÇÃO DO OBJECTO CENTRAL DA ANÁLISE}

Neste trabalho pretende-se compreender melhor a relação entre duas áreas de estudo fundamentais nos campos dos Estudos Políticos e dos Estudos Internacionais: a Política Externa e as Políticas Públicas. Que interacções existem entre estes dois temas? Que semelhanças ou diferenças apresentam? São norteados pelos mesmos propósitos, ou atendem aos mesmos princípios? Como se entende o Estado, a participação democrática, o processo de tomada de decisões, ou a responsabilidade/responsabilização pública (public accountability) em cada uma destas sub-disciplinas? Que evoluções tem havido na forma como se concebem esses conceitos-chave? Poderemos testemunhar uma cada vez maior aproximação entre estes âmbitos? Há vantagem nessa aproximação?

Escolheu-se este tema partindo de uma acepção que nos pareceu comum à medida que se revia a literatura de ambas as áreas; na verdade, é por demais corrente no âmbito da Política Externa e das Relações Internacionais ${ }^{3}$ um alegado “consenso de que a política externa sempre foi considerada como "externa" aos estados e distinta de toda e qualquer política doméstica” (Sanchez et. al., 2006, p. 125), que trespassa numa quantidade

\footnotetext{
${ }^{3}$ Para esclarecer a diferença conceptual entre Política Externa e Relações Internacionais, parece-nos que será relevante recorrer a uma revisão feita por Rodrigues (2004) aquando da sua tese de mestrado: "Como distinção de política internacional e política externa, o termo Relações Internacionais pode referir-se a todas as formas de interacção entre os membros de sociedades separadas. O estudo das relações internacionais inclui a análise das políticas externas ou processos políticos entre Estados. Contudo, deverão ser incluídos nessa análise, os estudos, por exemplo, de uniões de comércio internacional, da Cruz Vermelha Internacional, turismo, comércio internacional, transportes, comunicações e o desenvolvimento de valores e ética internacionais. Apesar do nascimento de outros actores internacionais, o Estado permanece como o actor central das relações internacionais. (...) Para a política externa, o Estado procura responder ao comportamento de outros actores internacionais e, de uma maneira geral, agir de acordo com os seus princípios quando o ambiente é favorável e transformar esse mesmo ambiente quando este se apresenta desfavorável. Noutros termos, o Estado procura, através da política externa, manter ou aumentar o seu peso e influência fora do seu território nacional. Uma das características importantes da política externa e que a distingue das demais políticas, é ter como campo de acção um espaço que escapa em grande parte ao seu próprio controlo. (...) Por outro lado, se olharmos para a política internacional na perspectiva de Estados individuais, em vez do Estado como parte de um sistema internacional em que está integrado, não encontramos muitas diferenças. Por aí se vê que são as condições internas dos Estados que acabam por mais influenciar a política dos mesmos. Guerras, alianças, imperialismo, manobras diplomáticas, isolamento e os imensos objectivos da acção diplomática, podem ser vistos como resultado das pressões políticas domésticas, ideologias nacionais, opinião pública ou necessidades económicas e sociais. Para analisarmos a política internacional e a política externa dos Estados, temos também que nos concentrar nas acções e comportamentos individuais dos homens de Estado, nomeadamente as suas ideologias, motivações, percepções, valores. São eles que acabam por estar empossados para tomar decisões em nome dos Estados.” (pp. 45-6)
} 
avassaladora a produção científica na área (largamente influenciada pelas teorias que exploraremos mais à frente, as mais subscritas nesse campo de estudos), mas também no senso comum, nomeadamente quanto se olha para a percepção da formação do interesse e objectivos nacionais para o exterior. Por outro lado, em toda a literatura que revimos na área das Políticas Públicas, também não parecia menos evidente uma "concepção corrente de que apenas as políticas domésticas seriam consideradas "políticas públicas", ou seja, respostas do Estado a situações socialmente problematizadas” (Sanchez et. al., 2006, p. 125), e de que, portanto, essa é uma área que lida fundamentalmente com o que o Estado escolhe ou não fazer, recorrendo à acção exclusivamente dentro das suas fronteiras (para resolver problemas internos, onde é soberano) atendendo à emergência, também ela interna, de questões a serem resolvidas. Desta forma, parece haver uma fronteira claramente definida entre uma e outra área - com interacções ou interferências, é certo, mas salientando-se sempre que estas teriam processos de formulação totalmente diferentes, e que até a própria actividade política associada a cada uma destas seria claramente distinta.

Assim, ao longo deste trabalho exploraremos, primeiramente, as teorias fundadoras das Relações Internacionais, o Realismo e o Liberalismo, particularmente na forma como concebem o Estado e entendem os processos ou fenómenos domésticos e internacionais, nomeadamente se estes são autónomos uns dos outros, o mesmo se aplicando às decisões tomadas para cada um dos âmbitos. Não deixaremos de proceder a esta tarefa sem nela incluir as principais visões sobre o Sistema Internacional, a opinião pública, e as alterações na vida internacional em cada uma destas teorias, que consideramos relevantes para as conclusões que procuraremos traçar adiante. Em seguida, vamos centrar-nos em algumas definições de Políticas Públicas e, em particular, em alguns conceitos ou ideias centrais dessa área que nos parecem pertinentes numa melhor compreensão da distância entre as Políticas Públicas e a Política Externa. Na parte que segue olharemos para a Foreign Policy Analysis (Análise de Política Externa, em português) ${ }^{4}$, argumentando que o surgimento destes estudos, quase formando uma nova disciplina (Freire e Vinha, 2011) apontam para uma aproximação aos pressupostos teóricos e ideias basilares das Políticas Públicas. Por fim, olharemos para uma série de artigos onde os seus autores procuraram relacionar as

\footnotetext{
4 Atendendo a que o conceito em português é praticamente desconhecido e até banalizado por muitos cientistas sociais, utilizar-se-á aqui, sempre que possível, a designação em inglês e não em português. Veja-se o estudo praticamente pioneiro de Pedro Emanuel Mendes (2012, p. 26), para quem "de um ponto de vista substantivo, o estudo analítico da política externa (Foreign Policy Analysis) em Portugal é praticamente inexistente. Ou seja, não existem estudos que, pela sua quantidade e qualidade, levem a afirmar que a Análise da Política Externa exista como campo de estudo específico em Portugal”.
} 
Política Externa e Política Pública num só debate, tentando "identificar as políticas interna, externa e internacional como um continuum de um mesmo processo decisório" (Sanchez et. al., 2006, p. 125). O nosso objectivo será compreender se essas propostas tiveram, ou poderão vir a ter, sucesso no futuro de ambas as disciplinas.

\section{AS TEORIAS FUNDADORAS DAS RELAÇÕES INTERNACIONAIS: REALISMO E LIBERALISMO. PERSPECTIVAS SOBRE A POLÍTICA EXTERNA E O ESTADO}

Em suma, as teorias das Relações Internacionais permitem-nos, por um lado, estruturar e avançar métodos e conceitos que permitam compreender a política mundial, os seus elementos fundamentais e funcionamento, bem como prever e explicar os acontecimentos mais relevantes que ocorram no normal funcionamento do sistema internacional. (Nogueira e Messari, 2005). Interessa-nos particularmente, naquilo que é a história bem conhecida dos seus "grandes debates", o primeiro dos ocorridos, entre o Realismo e o Liberalismo (ou Idealismo), e que se centrava em compreender se a disciplina se centrava em compreender o mundo como ele existe (Realistas) ou o mundo como ele deveria ser (Idealistas). Mais do que um debate situado no tempo, bem definido, acreditamos que este é um debate em contínuo que ainda hoje é central para a compreensão da disciplina, situando-se afinal presentemente, de uma forma ou doutra, as posições dos investigadores em Relações Internacionais numa destas teorias, nomeadamente nas suas variantes renovadas. Para além disso, são as duas teorias mais interessantes de analisar quando relacionadas com o tema das Políticas Públicas, tanto nas posições divergentes como nas convergentes que toma quanto ao Estado, racionalidade, interesse nacional, democracia e opinião pública.

O Realismo entende o Estado como uma "caixa-negra" e compreende o seu funcionamento através do modelo da bola de bilhar (billiard ball). Desta forma, abstraemse dos processos internos de tomada de decisão (e da sua complexidade) e das motivações politicas que levam os Estados a agir no plano internacional destacando exclusivamente a dinâmica da relação entre essas "caixas" ou essas "bolas". Para os seus autores, o Estado é um actor unitário e racional que age de maneira constante e homogénea (representando o conjunto dos seus membros de forma igual) e em defesa do interesse nacional. Essa racionalidade é percebida na defesa de um interesse nacional a um nível internacional, tendo por propósito os maiores ganhos a menor custo (custo-benefício), de forma 
totalmente amoral (Fernandes, 2009). Desta forma, a teoria salienta o consenso entre os actores internos em relação a esse interesse nacional, comum a todos e facilmente identificável, enquanto se nega a política presente nas decisões (Nogueira e Messari, 2005). Os grandes temas abordados por esta teoria são, em suma, o Estado, poder, sobrevivência, anarquia, auto-ajuda (todos estes referentes a como o Estado actua e sobrevive no Sistema Internacional) (Santos, 2007; Nogueira e Messari, 2005). Assim, temos uma política doméstica pouco relevante para a formação da política externa (porque esta é específica e racional), e níveis doméstico e internacional efectivamente separados - e sendo a dimensão internacional perfeitamente autónoma. Por fim, note-se que desde a queda do Muro de Berlim e o fim da Guerra Fria há uma série de autores realistas que têm posto em causa alguns destes postulados, de onde destacamos Fareed Zakaria, que voltou a olhar para as questões de política interna, desprezando a tradicional fronteira entre questões nacionais e internacionais, bem como a autonomia das questões internacionais, e afirmando que as questões internas têm um papel significativo na formação da política externa dos estados, com consequências particularmente relevantes no caso das questões internas das grandes potências (Nogueira e Messari, 2005). Desta forma, salientamos as novas correntes realistas que repensam e desconstroem praticamente a totalidade dos pressupostos basilares da teoria realista tradicional.

Já para o Liberalismo, o facto de o Sistema Internacional viver na eminência do conflito cria uma "ameaça permanente à liberdade no interior dos Estados" (Nogueira e Messari, 2005, p. 61). Assim, promover a paz mundial deve ser o objectivo central de Política Externa, sendo a única forma de provocar o fomento de bem-estar dos cidadãos. Por outro lado, a generalidade dos autores, inspirada em Kant, acredita que a guerra apenas aconteceria em casos extremos quando o poder é baseado na representação de interesses colectivos. Com a discussão que é inerente ao governo democrático, a justificação racional e legítima que exigida para os objectivos e caminhos traçados é essencial quanto o governo exerce o seu poder em nome da cidadania, pelo que a política externa se torna mais prudente e democrática, "comprometida com os interesses da sociedade em geral" (Nogueira e Messari, 2005, p. 64-5). É importante compreender que, para esta visão, “os processos de política externa estadual e os processos tradicionais envolvem conflito, negociação, aliança e compromisso, não conduzindo necessariamente a resultados óptimos", e que, quanto às temáticas tidas como mais importantes, há uma "agenda múltipla com as temáticas do bem-estar sócio-económico a ocuparem um lugar tão 
importante como a segurança nacional" (Fernandes, 2009, p. 80). Note-se ainda a importância que tem para estes autores o papel da opinião pública, já que o governo representativo implica o envolvimento da sociedade para uma tomada de decisão, o debate público e um resultado transparente, não só para os cidadãos nacionais mas até para o plano internacional, para os outros actores, e assim, evitando diplomacias escondidas ou jogos de poder secretos, contribuir para a paz mundial através das políticas externas individuais dos Estados (Nogueira e Messari, 2005).

No pós-Segunda Guerra Mundial, embora possuindo alicerces histórico-filosóficos anteriores (Fernandes, 2009) esta teoria procura demonstrar que quer mais do que simplesmente descrever o mundo como ele deveria ser, mas enfatizar como é possível reforçar a cooperação no Sistema Internacional, para além da promoção do livre-comércio e da democracia já há muito defendidos. Surge o funcionalismo, entendendo que a criação de organizações internacionais para assuntos específicos poderiam levar, por um efeito de spill-over, ao aprofundar da cooperação. Pode ser definida como uma "ampliação gradual dos processos racionais de organização das políticas públicas em âmbito internacional" (Nogueira e Messari, 2005, p. 77), num contexto de importância crescente das Organizações Internacionais Governamentais, em que este modo de organização das políticas é visto como promotor de uma eficiência funcional - ou seja, vê uma espécie de progresso da técnica como essencial para a cooperação e a paz. Outra das perspectivas que emergem no âmbito mais geral no liberalismo é a da Interdependência Complexa, particularmente estruturada e conceptualizada por Keohane e Nye. Entendem que é mais difícil de distinguir aquela fronteira entre o doméstico e o internacional, as interconexões multiplicam-se e atravessam as fronteiras dos Estados; e os actores participam, de forma crescente, em ambos os espaços. Não há um “interesse nacional”, e o Estado não é visto como um ator unitário, mas como "uma arena em que os interesses de diferentes grupos da sociedade se enfrentam, [portanto] já não podemos inferir o interesse nacional do comportamento do Estado" (Nogueira e Messari, 2005, p. 87). Portanto, fazendo uma espécie de ponte entre Realismo e Liberalismo, é importante compreender os interesses dos actores individuais dentro do Estado, para compreendermos a acção efectiva do Estado na procura de uma Política Externa. Um conjunto de autores significativo salienta ainda a importância do meio (internacional) na produção de uma estratégia individual (estatal), em que a protecção de informações continua a fazer parte do ambiente inter-estatal diário. Todavia, esta teoria, o institucionalismo liberal, salienta o papel das instituições na cooperação, apresentando-as não como meros meios de poder dos estados mais fortes, mas 
afectando os interesses e motivações das acções dos Estados. Portanto, estas instituições têm um propósito válido, e, fazendo alterar os incentivos e custos que um Estado percepciona, provoca alterações significativas na sua acção ${ }^{5}$.

Assim, com esta revisão das principais posições dos autores que subscrevem cada uma destas teorias, ficámos com uma perspectiva ampla sobre como se concebem o Estado e a Política Externa nas Relações Internacionais. Procurámos estas teorias convencionais não por serem, de forma algo redundante, as mais consensuais, mas porque achámos que seriam as que trariam um maior valor acrescentado a esta análise da fronteira entre Políticas Públicas e Política Externa ${ }^{6}$. Conseguimos traçar muitas semelhanças, mas também algumas diferenças pertinentes, entre o Realismo e o Liberalismo. Em suma, não deixamos de reconhecer a (crescente) pluralidade de actores nas Relações Internacionais, mas, pretendendo manter ao mesmo tempo um olhar nas Políticas Públicas, era para nós essencial focar o olhar na acção do Estado, e estas duas propostas teóricas são sem dúvida as melhores para tal objectivo.

\section{POLÍTICAS PÚBLICAS: DEFINIÇÕES E CONCEITOS ESSENCIAIS}

Olhando para algumas das definições mais correntes de políticas públicas, poderíamos salientar a de Anderson (1975), “um conjunto de acções intencionais seguido por um ator ou conjunto de atores ao lidar com um problema ou questão de interesse... As políticas públicas são as políticas desenvolvidas pelos órgãos e autoridades do governo"7, a de Jenkins (1978) "um conjunto de decisões inter-relacionadas tomadas por um ator político ou grupo de atores, respeitantes à selecção de metas e os meios para atingi-las

\footnotetext{
5 "Ao contrário de serem apenas um reflexo dos interesses dos mais poderosos, as instituições tem influência própria sobre as ações estatais na medida em que afetam seus incentivos e custos e (...) ajudam na compreensão do papel, dos interesses e das motivações dos Estados. Em outras palavras, as instituições importam, não são meros instrumentos ou construções jurídicas supérfluas." (Nogueira e Messari, 2005, pp. 95-6)

6 Tendo em conta, por exemplo, que, no âmbito das teorias marxistas das Relações Internacionais, “deslocando (...) o foco do Estado para o sistema capitalista mundial, o próprio Marx (...) não tinha interesse particular, em suas análises, na diferenciação entre o doméstico e o internacional, preferindo investigar o movimento do capital por meio das fronteiras e em escala mundial" (Nogueira e Messari, 2005, p. 12), e que, provavelmente, a única outra que poderia trazer contributos significativos a esta análise seria a Teoria Crítica, mas as óbvias contingências de espaço não permitem que ela seja aqui explorada convenientemente.

7 Tradução nossa.
} 
dentro de uma situação determinada", mas uma das mais conhecidas será certamente a de Dye (1972), “o que o governo escolhe fazer ou não fazer". Portanto, em suma, falamos de escolhas conscientes, de decisões governamentais (e não de outros actores), e que tanto quando falamos de alterar uma realidade como quando se pretende mantê-la como está falamos, efectivamente, de políticas públicas (Howlett, 2011). Como salienta Howlett, isto não nos permite saber muito sobre os processos que levam às políticas públicas ou quanto às decisões dos governos, porque são tomadas e com que conteúdo - e portanto que os meios e os objectivos são, também eles centrais, quer sejam mais abstractos ou concretizados em metas a cumprir, e distribuídos pelos vários níveis de aplicação dessas políticas.

Rapidamente a literatura salienta, de forma mais implícita ou explícita, o carácter doméstico de aplicação das políticas públicas, como resposta a necessidades ou problemas internos. "As políticas públicas são os resultados dos esforços feitos pelos governos para alterar aspectos do seu próprio comportamento ou do comportamento social, a fim de realizar algum fim ou propósito", entende Howlett (2011, pp. 19-20) ${ }^{10}$. Para Hill e Hupe (2011, p. 4), “embora [o conceito de] política deva ser distinguido [do conceito] de "decisão", é menos facilmente distinguível [do conceito] de 'administração'،‘11, envolvendo como elementos essenciais nesse conceito de políticas públicas: comportamento, intenção, acção e inacção, resultados (previsíveis ou não), propósitos, processos, relações (inter e intra-organizacionais), e um papel chave (mas não exclusivo) das instituições públicas ${ }^{12}$. Justamente por isto, no trabalho destes, centrado na fase da implementação, refere-se directamente que o contexto é determinante, pois "a "implementação" está sempre ligada a políticas específicas, como respostas particulares para problemas específicos na sociedade" (Hill \& Hupe, 2011, p. 5) ${ }^{13}$, portanto reforçando-se, implicitamente, o carácter interno do problema e da sua resolução.

Todavia, os autores de Políticas Públicas compreendem, pelo menos, de certa forma, o meio internacional nas políticas, nem que seja apenas pela sua influência no campo interno. "Compreender as ações do governo ao nível doméstico exige cada vez mais a consciência detalhada dos limites e oportunidades previstos por acordos internacionais,

\footnotetext{
8 Tradução nossa.

9 Tradução nossa.

10 Tradução nossa.

11 Tradução nossa.

12 Uma enumeração de conceitos em análise de Políticas Públicas ainda mais detalhada e estruturada pode ser encontrada em Cochran et. al., 2012, pp. 5-16

13 Tradução nossa.
} 
tratados e convenções" (Howlett, Ramesh \& Perl, 2009, pp. 6-7) ${ }^{14}$. Não queremos aqui fugir da compreensão de que os governos não podem escolher objectivos inatingíveis ou criar expectativas irrealistas, mas que, na medida das suas possibilidades, independentemente do nível onde as suas políticas criem impacto, o façam buscando efectivamente a melhoria de algum processo que de tal necessite ${ }^{15}$. Giandomenico Majone (2008, p. 241) também reflecte no mesmo sentido, em particular com o aumento da interdependência entre os países, tanto económica como política, uma vez que normalmente se propõe que fenómenos de integração reduzem as opções democráticas dentro de um estado. A sua posição é diametralmente oposta: "Uma hipótese alternativa é que o aprofundamento da integração económica pode realmente melhorar a qualidade da tomada de decisões, tornando os líderes nacionais mais conscientes dos impactos internacionais das suas decisões, mais dispostos a cooperar internacionalmente, e mais abertos a ideias e sugestões provenientes dos seus homólogos estrangeiros, de instituições internacionais e de organizações não-governamentais"16, embora sem negar que os processos de integração também poderão levar a uma corrosão dos processos de formulação e decisão das políticas públicas. Na verdade, há mais de 20 anos que nas Relações Internacionais se defende esta tese (de certa forma, explicámos no capítulo anterior alguns dos seus contornos), pelo que concluímos que seria claramente positivo que o diálogo entre estas duas áreas de estudo ocorresse mais frequente, mas sobretudo se salienta que as Políticas Públicas ainda lidam mal com o processo de globalização, nas suas dimensões económica, política e social, e têm sérias dificuldades para se adaptar à complexidade de processos sociais crescentemente globalizados. A "experiência

\footnotetext{
14 Tradução nossa.

15 "Independentemente de como é conduzida, a ideia de desenho de uma política está indissoluvelmente ligada com a ideia de melhorar as ações do governo através da consideração consciente, na fase de elaboração das políticas, dos prováveis resultados de atividades de implementação de políticas. Esta é uma preocupação tanto para os actores não-governamentais preocupados com terem de suportar os custos das falhas e incompetência de governo, bem como para os actores governamentais que podem ser incumbidos de realizar tarefas impossíveis e atender a expectativas irrealistas. Independentemente do regime e tipo de problema, e independentemente do peso específico dado pelos governos a diferentes objetivos (...), todos os governos desejam ter os seus objetivos efetivamente alcançados e geralmente desejam fazê-lo de uma forma eficiente, isto é, com um mínimo de esforço e custo. Assim, todos os governos (...) estão interessados em aplicar o conhecimento e experiência disponíveis sobre questões de políticas públicas, de modo a assegurar a realização mais ou menos eficiente e eficaz dos seus objectivos" (Howlett, 2011, p. 21; tradução nossa)

16 Tradução nossa.
} 
estrangeira" continua apenas a ser relevante para a cópia ou inspiração de modelos de políticas para o contexto doméstico, aquele que, pelos vistos, realmente importa ${ }^{17}$.

"Os cientistas políticos procuram [1] compreender e explicar o mundo da política (...), [2] aplicar o conhecimento para resolver problemas práticos, [3] canalizar (...) a mobilização da população por caminhos guiados pela compreensão e informação" (Cochran et. al., 2012, pp. 2-3) ${ }^{18}$. De certa forma, tem sido isso que temos praticado aqui, ao defender que uma aproximação entre as Políticas Públicas e a Política Externa poderia contribuir de forma frutífera para ambas. Isso é particularmente notório, como já começámos a expor, com a globalização a ser vista por tais autores como de certa forma escolhendo e impondo as opções políticas dos decisores, e estando completamente fora do controlo dos estados e dos actores políticos locais, e portanto sendo responsável pela retracção das políticas públicas, responsável por nada menos que a privatização e o tecnicismo das políticas, mais que dos imperativos de responsabilidade democrática (Hay, 2008). Este mesmo autor defende que caminhamos para Políticas Públicas Globais, embora coloque dúvidas sobre a forma democrática e pública em que possam ser decididas, pelo menos no presente. Assim, a maior parte dos autores ainda se encontram, de certa forma, algo perdidos à procura das alterações que marcaram o estado-nação e a política mundial, e ou acreditam que tais decisões, agora globais ${ }^{19}$, decidirão tudo e serão a única chave para resolver os problemas (como Hay), agora demasiadamente complexos para serem resolvidos a nível nacional" ${ }^{20}$ ou "a verdade é que o poder de decisão e capacidade e vontade para implementar permanece em grande parte localizada dentro de Estadosnação", e portanto "vários problemas e questões podem muito bem ser cada vez mais construídos em termos internacionais e globais, mas a tomada de decisões e implementação ainda permanecem como domínios que devem ser analisados no contexto dos Estadosnação" (Parsons, 2005, pp. 242-3) ${ }^{2122}$, compreendendo uma globalização política marcada

\footnotetext{
17 “Os decisores políticos tendem a começar por procurar informações por perto; alguma "identificação subjetiva" com os seus homólogos noutros locais é bastante provável. A próxima etapa do processo consiste na modelagem ou abstracção dos programas existentes, a fim de avaliar os seus componentes essenciais: de modo a poder servir como material transferível, a experiência estrangeira deve ser abstraída do contexto em que está inserida. Em seguida, um programa pode ser simplesmente copiado de outro lugar ou emulado, o que significa ajustá-lo de alguma forma à nova circunstância doméstica. Combinando elementos de mais de um programa em mais de um lugar leva a uma espécie de hibridação ou síntese, enquanto que a base na experiência em outros lugares serve como estímulo intelectual ou inspiração para o novo programa". (Freeman, 2008, p. 376; tradução nossa)

18 Tradução nossa.

19 para a compreensão da emergência do 'global', as complexidades que lhe são inerentes e, sobretudo, as mudanças que acarreta em todos os domínios da vida e, particularmente, nas formas como vemos o mundo e o analisamos, veja-se Urry (2005).

20 inspirámo-nos aqui nas formulações e na linguagem apresentadas por Beck (2004).

21 Tradução nossa.
} 
pela fragmentação dos poderes, mas não aceitando que isso implique uma renovada visão sobre os processos e os conceitos tradicionais de Políticas Públicas. Para Howlett, Ramesh \& Perl (2009, p. 75), “a formulação de políticas é muito mais uma preocupação nacional envolvendo os governos nacionais e os seus cidadãos (...). No entanto, o sistema internacional também é cada vez mais vital na formação das escolhas de políticas públicas no âmbito nacional, bem como no desenvolvimento das políticas" ${ }^{23}$, embora a explanação que se faz nas páginas seguintes não prime propriamente pela clareza. Depois de se tentar compreender quais os actores internacionais, tratados e convenções mais relevantes, a exposição é, apenas e só, descritiva, salientando que "o reconhecimento da influência do sistema internacional sobre as políticas públicas nacionais é um dos desenvolvimentos recentes mais emocionantes na disciplina. Enquanto o sistema internacional, provavelmente, sempre afetou as políticas públicas em alguma medida, o seu âmbito e intensidade tem aumentado bastante nos últimos tempos" ${ }^{24}$, portanto reforçando o cepticismo quanto às influências internacionais nas políticas públicas nacionais, um cepticismo que sempre atravessou a disciplina. E, na verdade, não consegue descrever de forma minimamente sistemática tanto os meios, as formas e os mecanismos que interligam os processos políticos de índole interna com o sistema internacional (Howlett, Ramesh \& Perl, 2009), considerando-os sempre como particularmente difíceis, complexos, mas nunca os conseguindo, na prática, concretizar.

Por fim, interessaram-nos estes temas pois comungamos da visão de Parsons (2005, p. 614) quando defende que é necessário considerar “os propósitos mais amplos da política pública como envolvendo a clarificação e esclarecimento, o pleno desenvolvimento dos indivíduos na sociedade, bem como o desenvolvimento de consentimento, o consenso, a consciência social e legitimidade, ao invés de simplesmente a entrega de produtos e serviços" ${ }^{2526}$, temas recorrentemente focados, tratados e enfatizados no âmbito da literatura

\footnotetext{
${ }^{22}$ Howlett (2011, pp. 6-7; tradução nossa) entende exactamente o mesmo: “(...) É necessário reconhecer que existem graves lacunas na nossa compreensão do funcionamento e as características da globalização e as suas consequências nas políticas públicas. (...) Ao contrário do que normalmente se pensa e é muitas vezes defendido, na nossa era global o estado doméstico continua longe de estar oprimido e de não ter capacidade de decisão autônoma; e a fonte de muitas das mudanças nos padrões de definição de políticas e escolha dos seus instrumentos que encontramos na sociedade contemporânea, muitas vezes, encontra-se no mercado interno e não na arena internacional ". "Por isso, até hoje, o real impacto da globalização sobre o desenho das políticas internas do estado é muito menor do que muitas vezes se alega (...)", centrando-se simplesmente em constrangimentos directos e desvalorizando, nomeadamente, as mudanças económicas levadas a cabo pelas organizações promotoras da globalização.

23 Tradução nossa.

24 Tradução nossa.

25 Tradução nossa.
} 
das políticas públicas ${ }^{27}$. A descentralização, o controle democrático, a participação dos cidadãos devem ser objectivos das políticas ou meios essenciais em que estas se desenvolvam, melhorando então, efectivamente, o costume político democrático numa sociedade. O pluralismo e a comunidade encarregar-se-ão de fortalecer a cidadania (Parsons, 2005) e a justiça, fortalecendo a eficiência e eficácia das políticas que se pretendem implementar. Por isso, "[a] criação de arenas públicas e fóruns abertos à discussão" (Ingram \& Schneider, 2008, p. 174), uma acção mais comprometida por parte dos cidadãos assente num diálogo efectivo entre o governo e os governados, e, normalmente esquecida, uma resposta e responsabilidade que tenha em conta os actos, os resultados, e as intenções iniciais. Na verdade, "isto implica transparência nas transações e divulgação total dos interesses [envolvidos]” (Ingram \& Schneider, 2008, p. 184) ${ }^{28}$, o que torna essencial que os cidadãos tenham acesso à informação que lhes permitirá um maior conhecimento sobre os temas, bem como a sua mobilização e participação. A avaliação e as medidas de performance (nos famosos termos de 'benchmarking' ou 'melhores práticas') apresentam-se como tarefas que devem expandir-se pelos governos, quer promovidas por estes quer pelos seus cidadãos, por se apresentarem como a melhor forma de corrigir os problemas que minam a democracia e os seus meios de sobrevivência (Ingram \& Schneider, 2008).

\section{FOREIGN POLICY ANALYSIS: UMA APROXIMAÇÃO AO CONHECIMENTO DAS POLÍTICAS PÚBLICAS?}

A Foreign Policy Analysis é uma área de estudo que tem vindo a emergir no campo das Relações Internacionais, uma sub-disciplina que aborda este tema tendo em conta outras áreas científicas como a Ciência Política ou os Estudos Políticos (Santos, 2007). Esta

\footnotetext{
${ }^{26} \mathrm{Ou}$, dito de outra forma: "A democracia complica a formulação de políticas e as tarefas de implementação numa sociedade capitalista, porque a sua presença significa que decisores políticos já não se podem concentrar em servir apenas os interesses do Estado e os interesses dos seus aliados de negócios, de acordo com os princípios de um paradigma de política liberal pura. Nas democracias, os decisores políticos têm de, pelo menos, parecem estar a atender as preocupações [das pessoas] (...), que têm interesses diferentes e muitas vezes contraditórios, que precisam de ser constantemente ponderados e são inerentemente instáveis”. Howlett, Ramesh \& Perl (2009, p. 58; tradução nossa)

27 È justamente porque esta questão da "public accountability" das decisões é um tema tão retratado na literatura das políticas públicas que também o trazemos aqui; mas, igualmente, tendo em conta o avolumar de autores e perspectivas teóricas nas Relações Internacionais e, nomeadamente, nos estudos de política externa, que vêem reforçando justamente a mesma dimensão, ao mesmo tempo que rebatem com algum sucesso os pressupostos realistas sobre a necessidade de secretismo e de confidencialidade para garantir a segurança e defesa do estado e dos seus cidadãos.

28 Tradução nossa.
} 
nova área, centrada em compreender como é que o Estado forma a sua política externa, emergiu no pós Segunda Guerra Mundial e, entre as perspectivas renovadas que os autores trouxeram àquela data, salientam-se: por um lado, a necessidade de ver o mundo de quem toma as decisões como estes o vêem; compreender a diferença da visão que o decisor tem do meio onde aplica a política da forma que realmente tem, bem como a diferença entre os resultados percepcionados pelo decisor dos realmente obtidos; por último, a necessidade de incluir perspectivas de outras ciências para compreender a complexidade da política externa, com causas e consequências que actuam em vários níveis. Assim, a disciplina teria como pressupostos teóricos básicos: "o conhecimento das especificidades dos indivíduos envolvidos nas decisões de política externa é crucial para a compreensão das escolhas; a informação sobre estas especificidades deve ser incorporada na construção de teorias transnacionais e de médio-alcance; as teorias resultantes devem integrar múltiplos níveis de análise; e a compreensão do processo de formulação da política externa é tão importante, se não mais importante, do que a compreensão dos outputs da política externa" (Freire e Vinha, 2011, p. 15). Deste modo, emergiram trabalhos sobre as estruturas dos grupos decisores, os valores e emoções destes, e, por último, as tentativas para uma política externa comparada. Para além disto, à medida que as teorias tradicionais das Relações Internacionais têm mais dificuldade em explicar o mundo contemporâneo, este olhar para os indivíduos, para a estruturas e procedimentos envolvidos no processo de decisão reforça-se ${ }^{29}$. Esta análise do processo de decisão em política externa, olhando para processos, declarações e comportamentos (Freire e Vinha, 2011, p. 18) compreende tanto actores como acções internos e externos, quer todos estes sejam intencionais ou não ${ }^{30}$. Ainda se acrescenta que, desta forma, se tem em conta actores nas suas várias localizações espaciais no Sistema Internacional, um número de áreas científicas mas também de intervenção alargado, mas que todavia não são estanques, interligando-se e influenciando-

29 Para uma revisão histórica da Foreign Policy Analysis que tem em conta como nenhum dos outros trabalhos que analisámos as posições das teorias das Relações Internacionais na visão dessa nova subtemática, ver Milani e Pinheiro (2013)

${ }^{30}$ Veja-se, para este efeito, a definição de Freire e Vinha (2011, p. 18) de 'política externa': “o conjunto de objectivos, estratégias e instrumentos que decisores dotados de autoridade escolhem e aplicam a entidades externas à sua jurisdição política, bem como os resultados não intencionais dessas mesmas acções.” 
$\mathrm{se}^{31}$. O ambiente político internacional, particularmente complexo, apenas complica tanto as decisões e as estratégias como as análises científicas sobre as mesmas. Tal ambiente pode ser visto como contendo uma multiplicidade de actores, com assimetrias notáveis no acesso à tecnologia, que praticam o engano, a fraude, ou o secretismo no seu dia-a-dia, com as dificuldades inerentes à informação que já conhecíamos dos estudos económicos (inexistente, ambígua, inconsistente), para além de que os temas são cada vez mais complexos e transversais (portanto interdependentes), e que o ambiente político tem de estar em constante alerta na análise de tal informação (Freire e Vinha, 2011) ${ }^{32}$. Estas três novas e diferentes abordagens ao estudo da política externa, nomeadamente, a política externa comparada, o enfoque no processo de formulação e decisão em política externa, ou ainda a abordagem ao contexto da política externa permitem uma melhor compreensão tanto dos fenómenos da política externa como de grande parte da vida internacional. Ao mesmo tempo que falamos de perspectivas mais concretas, específicas e empiricamente testáveis do que as teorias gerais das Relações Internacionais, procura integrar conhecimentos tanto da Ciência Política como das Relações Internacionais, posicionandose sistematicamente numa posição intermédia entre o enfoque no Estado ou no sistema internacional, podendo obter explicações mais focadas e compreensivas para os fenómenos da vida internacional. Igualmente, com o objectivo de compreender não apenas os acontecimentos externos mas as dinâmicas da política interna, elementos como as dinâmicas, os actores e as fases de determinada decisão são fundamentais para compreendermos o resultado final obtido. Devemos ainda salientar que, ao afastarmo-nos de grandes teorias muito abstractas, os estudos sobre política externa poderão ultrapassar o estágio da descrição dos fenómenos, e, eventualmente, ganhar uma natureza efectivamente mais explicativa e até, contribuir para determinar a política externa do país, uma vez que os seus estudos serão mais valiosos para os actores envolvidos no processo decisório (Mendes, 2012; Hudson e Vore, 1995).

Em suma, desmontámos muito sucintamente aquela que é uma nova abordagem para compreender os assuntos internacionais e globais, e que se apresenta próxima como

\footnotetext{
31 Para compreender, com maior detalhe, os tipos de decisões em política externa bem como formas de decisão, ver Freire e Vinha (2011, pp. 33-5) (que também podem ser vistos em Mintz \& DeRouen Jr., 2010), que aqui, infelizmente, não podemos abordar, atendendo aos constrangimentos de espaço. "Abrir a caixanegra do estado" ou "reforçar a premissa de que atores e fatores domésticos não eram menos relevantes para a formulação e o conteúdo da política externa" é a linguagem comum deste tipo de trabalhos, e que, como veremos ao longo deste capítulo, muito os aproxima das Políticas Públicas. Ver Milani e Pinheiro (2013)

32 Tenha-se em conta que já nem detalhamos aqui a proximidade entre os determinantes das decisões de política externa (Mintz \& DeRouen Jr., 2010), ou que "o sistema de tomada de posição em política externa também pode ser visto como um conjunto de etapas. Estes são a recolha de informações, a sua interpretação, a formação de opções, a escolha, e a fase de implementação" (Inamete, 2001, pp. 18-9;tradução nossa)
} 
nunca das políticas públicas. Conseguimos demonstrar que é possível que uma ciência centrada na análise política que tem olhado sobretudo para o campo doméstico pode trazer um contributo positivo para a política externa. Mostrámos as variadíssimas semelhanças entre a Foreign Policy Analysis e as Políticas Públicas, mas também que diferenças as marcam $^{33}$. Infelizmente, não pudemos trabalhar sobre como é que se poderá fazer a análise de um assunto no mundo real (ou de alguma hipótese plausível) atendendo a tais métodos $^{34}$, e os assuntos que já discutimos aquando da explanação das teorias, nomeadamente quanto ao secretismo que ainda envolve estes assuntos, tornam ainda mais difícil a resolução de problemas práticos quotidianos, e se concentrem mais em explicar como se procedeu de determinada forma no passado ${ }^{35}$.

\section{CONTRIBUTOS DAS POLÍTICAS PÚBLICAS PARA A POLÍTICA EXTERNA? DIÁLOGOS E VIZINHANÇAS}

Nesta parte mais terminal do nosso trabalho, aquilo a que iremos proceder é a uma crítica de um número de artigos que procuram já aproximar ambas as realidades que aqui explorámos. Sanchez et. al. (2006, p. 125), a que aqui já recorremos, procurou, ao analisar 20 anos de regulamentação constitucional brasileira, ter como propósito "identificar as políticas interna, externa e internacional como um continuum de um mesmo processo decisório". Embora uma maior distribuição de competências e um maior número de controlos a tal política externa (que a autora expõe ao longo do artigo) sejam visíveis, temos dificuldade em acreditar numa interdependência total e absoluta, em que estes níveis se

33 Como já referimos, por motivos de espaço não foi possível detalhar mais extensivamente esta questão, que pode ser analisada de forma abrangente em Mintz \& DeRouen Jr. (2010) ou Inamete (2001).

${ }_{34}$ Um exemplo de tal trabalho, para a caracterização da Política Externa Brasileira atendendo a estes princípios, poderá ser vista em Milani e Pinheiro (2013).

${ }^{35}$ É particularmente conhecido o estudo de Allison e Zelikow sobre a Crise dos Mísseis de Cuba, tido como um dos textos iniciais da Foreign Policy Analysis e como criando pontes entre o pensamento em políticas públicas, política externa e administração pública, mas de uma forma particularmente crítica e assertiva. "Na sua famosa obra 'Essence of Decision', Graham Allison oferece três tentativas de explicação de um incidente de política externa - a Crise dos Mísseis de Cuba de 1962. Investigando tanto o lado dos EUA como o soviético no presente caso, Allison mostra que o modelo do ator unitário e racional para a formação da política externa não é suficiente para explicar os elementos da crise. Avançando dois modelos adicionais como outras tentativas de explicação, o Modelo de Processo Organizacional e o Modelo de Política Burocrática (os primeiros, [sobre] factores intra-organizacionais, o segundo, factores interorganizacionais), permite que Allison explique mais detalhadamente o que aconteceu. Este uso de três níveis de análise também aponta para o desejo de integrar explicações em diferentes níveis, em vez de as segregar." Hudson (2005, p. 8; tradução nossa). Ver ainda Hill, 2006, pp. 115-6, pp. 135-6. 
afectem mutuamente a todo o tempo e sejam totalmente coordenados entre si. Também não podemos assegurar que em outros casos que não o estudado, ela esteja efectivamente mais plural (em termos dos actores) e complexa (quanto à estrutura decisória). Por outro lado, embora, como já mostrámos, consideramos a política externa como parte de um processo decisório mais vasto, não estamos seguros da visão de Pasquarelli (2010, p. 2279) quando defende que esta funciona "não como uma plataforma para ganhar eleições, mas como um meio de garantir maior autonomia e presença do país em questões internacionais". Para além disso, há que ter em conta a diversidade e pluralidade de interesses dos actores, mesmo dos políticos, numa mesma nação, partido ou grupo de interesse: "no nível nacional, os grupos domésticos (partidos, parlamentares, grupos de interesse) seguem seus interesses pressionando o governo para a prática de políticas favoráveis; já no nível internacional os governos nacionais (diplomatas, conselheiros) procuram maximizar sua habilidade para satisfazer pressões domésticas. Com isso, nenhum dos dois jogos pode ser ignorado pelos decisores centrais" (Pasquarelli, 2010, p. 2280). Procurou-se assim compreender que todos estes instrumentos podem ajudar a compreender as causas, os efeitos e as influências das mudanças ou continuidades das políticas (Pasquarelli, 2010), bem como argumentar que, num regime democrático e num Sistema Internacional onde pode vigorar o Direito Internacional (se os estados assim o entenderem) não podemos colocar-nos do lado do secretismo (na "defesa dos interesses nacionais") mas apenas no da public accountability, no que ele representa para a transparência e participação $\operatorname{social}^{36}$. Este entendimento decorre de uma posição que é factual e decorre do conhecimento científico, nomeadamente quanto compreendidas outras áreas do conhecimento; por outras palavras, nomeadamente, com o estudo da história diplomática de um país, se for feito de forma a atender tanto aos fenómenos internos como de política internacional, rapidamente concluímos que, ao contrário do que propõe, na sua essência, o realismo, não existe um distanciamento da comunidade nacional relativamente aos temas de política externa, que existem actores, grupos de interesse, burocracias, etc., que tentam activamente moldar a política externa do país (ver Macedo, 2006 e Telo, 2003). Daí resulta que, apesar de poder manter-se razoavelmente constante e algo resistente à mudança, a ideia de que é encontrada por um processo racional sem o envolvimento do

\footnotetext{
36 "A política externa era - e continua sendo em grande medida - uma prerrogativa do poder executivo (...), que ainda hoje é sujeita a poucos mecanismos de controle democrático, seja internamente ao governo ou vindos da sociedade. As informações a respeito dos processos decisórios que determinavam a pauta da política externa ou certos comportamentos internacionais não estavam disponíveis. O processo de nomeação dos representantes e diplomatas também era distante da participação e escrutínio da sociedade civil (...) bem como o comportamento em outras arenas internacionais" (Conectas Direitos Humanos, 2013)
} 
jogo político, de que é desinteressada, legítima e de certo modo um veículo da vontade e do interesse nacional não passa de uma mistificação. Assim, e mesmo que esta perspectiva de certa forma compatibilize visões realistas centradas em factores sistémicos e na constância e previsibilidade da política externa com visões mais liberais preocupadas com os factores domésticos e as interacções internas entre os actores, sem dúvida desclassifica o défice de transparência que afecta estas políticas. Sobretudo num contexto em que: a diplomacia contemporânea é essencialmente multilateral, parlamentar e pública; em que não é claro um unidade/interesse nacional facilmente identificável e comum a todos os cidadãos; e em que, ao mesmo tempo que temas relacionados com a segurança e defesa do Estado parecem ter cada vez um menor enfoque na vida desse próprio estado; é mais difícil justificar decisões estatais com propósitos e objectivos duvidosos, e tomadas de forma secreta e pouco transparente, argumentando a favor de um cálculo perfeitamente racional do posicionamento internacional que aquele estado deve assumir (o seu lugar no mundo, em suma) (ver Patrício, 2014). Acreditamos, com Milani e Pinheiro (2013, p. 32-33), que na actualidade, as formas de inserção de um país na cena regional e global são determinantes tanto para a distribuição interna dos poderes como para a gestão de assuntos mais transversais, normalmente através de novos mecanismos de coordenação, mas, sobretudo, subscrevemos a sua posição relativamente não apenas à colocação deste tema como qualquer outro no regime democrático, mas também da necessidade de reforçar o conhecimento teórico sobre o tema, dada a centralidade destas questões para o posicionamento internacional do país: "se admitimos que as práticas da política externa estão hoje mais próximas do cotidiano, que as escolhas estão relacionadas a interesses diversos e muitas vezes dispersos, que a política externa enfim não expressa um interesse nacional autoevidente, mas é resultado da competição, estamos por extensão trazendo para esse terreno a necessária discussão sobre a submissão da política externa aos controles e regras do regime democrático. Ao fazê-lo, (...) sublinham[os] a necessidade de maior rigor na utilização dos conceitos que constituem essa agenda de reflexão, uma vez que tais conceitos trazem, implicitamente, uma não desprezível carga política”. Os princípios e os objectivos dessa política externa são essenciais para se conseguir transformá-la num tema político relevante, em que a discussão ganha uma nova substância no que toca a escolher o rumo a seguir (d'Avila e Stuenkel, 2010). Por fim, o artigo de Lentner (2006, p. 169; tradução nossa) centrou-se em argumentar "pela unidade, paralelismo, e sobreposição entre os estudos de políticas públicas nacionais e estudos de política externa. Examina as razões 
para a clivagem e examina uma série de tentativas para encontrar soluções para o problema da interseção na fronteira entre a vida nacional e do ambiente internacional. Coloca a dicotomia num contexto mais amplo da ciência política como um todo e oferece sugestões sobre intercâmbios potencialmente frutíferos". As conclusões, propostas e desafios que Lentner traça são sem dúvida muito mais úteis e interessantes do que nós poderíamos traçar - nomeadamente, enquanto a Política Externa deve passar a incluir os participantes e os processos na sua análise, as alterações de longo prazo mais do que as análises de crises (que sempre fez), aqueles que trabalham em Políticas Públicas têm que ter em conta os governos estrangeiros e as ONG na sua análise, para além de propor trabalhos juntos entre as duas ciências, em como as agendas de uma afectam as de outra, por exemplo. "Esse envolvimento pode também fortalecer a análise política dentro da ciência política como um todo, e certamente fortalecer a análise política no contexto da imensa influência da análise económica na arena de formulação de políticas no âmbito da vida política e social nacional" (Lentner, 2006, p. 179; tradução nossa).

\section{NOTAS FINAIS}

Embora a maior parte dos trabalhos já desenvolvidos que procurem aproximar estas duas dimensões se centrem mais numa análise de segurança e defesa das políticas externas (Cochran et. al., 2012), continuamos a acreditar que o desenvolvimento de propostas empíricas que tenham em conta estas questões será a melhor forma de aproximar estas duas áreas. Nomeadamente, para o caso da Política Externa, falamos de trabalhos que tenham em conta os modelos de etapas e de sistema, amplamente trabalhados e desenvolvidos pelas Políticas Públicas (tanto do ponto de vista dos métodos e técnicas a utilizar, como do tipo de dados necessários para o seu estudo efectivo), mas sem esquecer o ambiente em que os eventos decorrem e o papel do passado (path dependency e a importância do passado, da história, por Pierson (2004)). Acreditamos que seguir o esquema de análise das políticas de Bardach (2012, p. xvii, xviii) terá, como principal função e utilidade relembrar os decisores de políticas públicas e os investigadores de todas as tarefas e escolhas centrais na estrutura dessas mesmas políticas. Ambas as abordagens parecem estar, finalmente, a chegar a métodos, técnicas, abordagens e, portanto, também a resultados mais próximos entre si, embora seja evidente o estado embrionário em que está o diálogo deliberado entre as duas áreas científicas, e que um 
intercâmbio entre as duas, se tivesse sido levado a cabo há mais tempo e de forma estruturada, poderia ter avançado grandemente o conhecimento nas duas áreas, podendo tanto as Políticas Públicas lidar hoje melhor com os fenómenos de globalização ou a dimensão internacional nas políticas públicas, ou a Análise de Política Externa ter chegado mais cedo à compreensão de que análises e teorias um pouco mais concretas do que as abordagens assaz abstractas das teorias tradicionais das Relações Internacionais, bem como o papel da dimensão nacional, mais complexificada do que tendo meramente o Estado como actor unitário e racional, levariam a uma explicação bastante mais compreensiva e bem-sucedida dos fenómenos internacionais e de orientação externa de um estado. Assim, e no seguimento do que defendem, entre vários outros, Parsons (2005), Ingram \& Schneider (2008), Howlett, Ramesh \& Perl (2009) ou Milani e Pinheiro (2013), se conseguirá contribuir para o conhecimento e um debate um pouco mais racional sobre as políticas - mas assegurando a importância do debate político, do espaço público democrático, das diferentes alternativas (Majone, 1989; Rodrigues e Silva, 2012) dos grupos de interesse e da opinião pública. Confiamos que numa governação democrática, o papel do governo deve ser o de intervir significativamente para "estimular a um melhor acesso à informação, para corrigir os desequilíbrios de poder e estereótipos prejudiciais e construções sociais entre as partes interessadas, e para criar arenas e esferas de discussão pública. Os analistas políticos devem estar preparados para revelar o enquadramento dos problemas e das construções sociais de elementos prejudiciais à democracia. Os analistas políticos também podem ser chamados para sugerir ferramentas alternativas políticas, regras e estruturas de implementação que facilitem as condições para a democracia" (Ingram \& Schneider, 2008, p. 184; tradução nossa) ${ }^{37}$. Sem dúvida, este parece-nos o dever tanto de quem trabalha em questões de Política Externa como em Políticas Públicas, e, em particular, de quem pretende construir pontes entre os estudos políticos e os estudos internacionais.

\footnotetext{
37 No mesmo sentido aponta Santos (2007, pp. 290-1): “a consciencialização progressiva dos dirigentes políticos sobre a imperatividade da consideração da influência das opiniões públicas transnacionais exercida sobre os contextos decisionais, no plano das políticas externas dos estados, tem conferido expressão identificada a um fenómeno evolutivo, inequivocamente histórico. Com efeito, o acesso progressivo das populações à informação e ao conhecimento, o efeito globalizante da realidade dos factos e da informação transmitida em tempo real pelos media, e o carácter aleatório, vago e difuso da origem das ameaças que têm como alvos objectivos as sociedades civis, têm determinado a acentuação crescente dos eleitorados sobre os processos de legitimação política dos dirigentes e dos decisores, projectando-se, em termos de efeitos concretos, nas relações internacionais, designadamente, no plano das decisões e da condução das acções de política externa dos estados (...)".
} 


\section{REFERÊNCIAS BIBLIOGRÁFICAS}

BARDACH, E. (2012). A Practical Guide for Policy Analysis: The Eightfold Path to More Effective Problem Solving. $4^{\text {th }}$ Ed.. CQ Press College

BECK, U. (2004). ¿Qué es la globalización?: falacias del globalismo, respuestas a la globalización. Trad. Bernardo Moreno y María Rosa Borras. Barcelona: Paidos

COCHRAN, C. E.; MAYER, L. C.; CARR, T. R.; CAYER, N. J.; MCKENZIE, M. J.; PECK, L. R. (2012). American Public Policy: An Introduction, 10th Edition. Boston: Wadsworth

CONECTAS DIREITOS HUMANOS (2013). Politica Externa e Direitos Humanos: Estratégias de ação para a sociedade civil. Um olhar a partir da experiência da Conectas no Brasil. São Paulo: Conectas Direitos Humanos

D'AVILA, L. F.; STUENKEL, O. (2010). O desafio de tornar a política externa relevante para o Brasil, in CLP Papers, n 3. São Paulo: Centro de Liderança Política

FERNANDES, J. P: T. (2009). Teorias das Relações Internacionais. Da Abordagem Clássica ao Debate Pós-Positivista. $2^{\text {a }}$ ed. Coimbra: Almedina

FREEMAN, R. (2008). Learning in Public Policy, in Moran, Michael; Rein, Martin; Goodin, Robert E. (2008). The Oxford handbook of public policy. Oxford: Oxford University Press

FREIRE, M. R.; DA VINHA, L. (2011), Política externa: modelos, actores e dinâmicas, in Maria Raquel Freire (org.), Política Externa: As Relações Internacionais em Mudança. Coimbra: Imprensa da Universidade de Coimbra, 13-54.

HAY, C. (2008). Globalization and Public Policy, in Moran, Michael; Rein, Martin; Goodin, Robert E. (2008). The Oxford handbook of public policy. Oxford: Oxford University Press

HILL, M. (2006). The Public Policy Process. $4^{\text {th }}$ ed.. Essex: Pearson Education Limited

HILL, M.; HUPE, P. (2011). Implementing Public Policy: an introduction to the study of operational governance. $2^{\text {nd }}$ ed.. London: Sage

HOWLETT, M.; RAMESH, M.; PERL, A. (2009). Studying Public Policy: policy cycles and policy subsystems. $3^{\text {rd }}$ ed.. Oxford: Oxford University Press

HOWLET'T, M. (2011). Designing Public Policies: principles and instruments. London: Routledge

HUDSON, V. M.; VORE, C. S. (1995). Foreign Policy Analisis Yesterday, Today, and Tomorrow. Mershon International Studies Review, Vol. 39, No. 2 (Oct., 1995), pp. 209-238

INAMETE, U. B. (2001). Foreign Policy Decision-Making in Nigeria. Michigan: Fairleigh Dickinson University Press 
INGRAM, H.; SCHNEIDER, A. L. (2008). Policy Analysis for Democracy, in Moran, Michael; Rein, Martin; Goodin, Robert E. (2008). The Oxford handbook of public policy. Oxford: Oxford University Press

LENTNER, H. H. (2006). Public Policy and Foreign Policy: Divergences, Intersections, Exchange, in Review of Policy Research, Volume 23, Number 1. Disponível em: http://works.bepress.com/howard_h_lentner/2 (consultado a 2014-06-12)

MACEDO, J. B. de (2006), História Diplomática de Portugal: Constantes e Linhas de Força. Estudo de Geopolitica. Lisboa: Tribuna da História

MAJONE, G. (1989). Evidence, Argument, \& Persuasion in the Policy Process. New Haven: Yale University Press

MAJONE, G. (2008). Agenda Setting, in Moran, Michael; Rein, Martin; Goodin, Robert E. (2008). The Oxford handbook of public policy. Oxford: Oxford University Press

MENDES, P. E. (2012). Portugal e a Europa. Factores de afastamento e aproximação da política externa portuguesa (1970-1978). CEPESE (Centro de Estudos da População, Economia e Sociedade). Disponível em http://www.cepese.pt/portal/investigacao/portugal-e-a-europafactores-de-afastamento-e-aproximacao-da-politica-externa-portuguesa-19701978/at download/file (consultado a 2014-01-16)

MILANI, C. ; PINHEIRO, L. (2013). Política Externa Brasileira: Os Desafios de sua Caracterização como Política Pública, in Contexto Internacional (PUC), Vol. 35, $\mathrm{n}^{\circ} 1$. Rio de Janeiro: Pontifícia Universidade Católica do Rio de Janeiro

MINTZ, A.; DEROUEN JR. (2010). Understanding Foreign Policy Decision Making. Cambridge: Cambridge University Press

MORAN, M; REIN, M.; GOODIN, R. E. (2008). The Oxford bandbook of public policy. Oxford: Oxford University Press

NOGUEIRA, J. P.; MESSARI, N. (2005). Teoria das Relações Internacionais: correntes e debates. Rio de Janeiro: Editora Elsevier.

PARSONS, W. (2005). Public policy: an introduction to the theory and practice of policy analysis. Cheltenham: Edward Elgar

PASQUARELLI, B. V. L. (2010). Política exterior como política pública: un análisis de la actividad diplomática brasileña durante el gobierno Lula, in XIV Encuentro de Latinoamericanistas Españoles: Actas del congreso internacional. Santiago de Compostela: Universidade de Santiago de Compostela, Centro Interdisciplinario de Estudios Americanistas Gumersindo Busto, Consejo Español de Estudios Iberoamericanos

PATRÍCIO, R. (2014), Política Externa, in MENDES, Nuno Canas e COUTINHO, Francisco Pereira (orgs.) (2014), Enciclopédia das Relações Internacionais. Lisboa: Dom Quixote 
PIERSON, P. (2004). Politics in Time: History, Institutions, and Social Analysis. Princeton University Press

RODRIGUES, R. J. S. (2004). "Dinâmicas económicas e política externa portuguesa nos países não lusófonos da SADC (1975-2002)". Dissertação de Mestrado. Universidade Técnica de Lisboa. Instituto Superior de Economia e Gestão. Disponível em: http://hdl.handle.net/10400.5/1271 (consultado a 2014-06-12)

RODRIGUES, M. de L.; SILVA, P. A. (2012). Introdução, in Rodrigues, Maria de Lurdes; Silva, Pedro Adão e (org.) (2012). Políticas Públicas em Portugal. Lisboa: Imprensa Nacional Casa da Moeda

SANCHEZ, M., SILVA, E., CARDOSO, E., SPÉCIE, P. (2006), Política Externa como Política Pública: uma análise pela Regulamentação Constitucional Brasileira (1967-1988), Revista de Sociologia e Politica, Curitiba, 27, p. 125-143

SANTOS, V. M. dos (2007). Introdução à Teoria das Relações Internacionais. Referências de Enquadramento Teórico-Analitico. Lisboa: Universidade Técnica de Lisboa, Instituto Superior de Ciências Sociais e Políticas

TELO, A. J. (2003). Portugal en los sistemas internacionales, in Telo, António José, e Gómez, Hipólito de la Torre, Portugal y España en los sistemas internacionales contemporáneos. Mérida: Editora Regional de Extremadura

URRY, J. (2005). Global Complexity. Cambridge: Polity 